\title{
Phytotherapy Research
}

\section{The role of curcumin administration in patients with major depressive disorder: Mini meta-analysis of clinical trials}

\begin{tabular}{|r|l|}
\hline Journal: & Phytotherapy Research \\
\hline Manuscript ID & PTR-15-1093.R1 \\
\hline Wiley - Manuscript type: & Review \\
\hline Date Submitted by the Author: & $29-$ Oct-2015 \\
\hline Complete List of Authors: & $\begin{array}{l}\text { Al-Karawi, Dalia; Al Kadhimiya Teaching Hospital, } \\
\text { Al Mamoori, Doaa; Baghdad Medical City, Emergency Medicine } \\
\text { Tayyar, Yaman; Griffith University, Medical Science }\end{array}$ \\
\hline Keyword: & curcumin, major depressive disorder, clinical effect \\
\hline
\end{tabular}

SCHOLARONE ${ }^{\text {IM }}$

Manuscripts 


\title{
The role of curcumin administration in patients with major depressive disorder: Mini meta-analysis of clinical trials
}

\author{
Dalia Al-Karawi, M.B.Ch.B \\ Al-Kadhimiya Teaching Hospital, Baghdad, Iraq \\ Doaa Alem Al Mamoori, M.B.Ch.B \\ Department of Emergency Medicine, Baghdad Medical City, Baghdad, Iraq. \\ Yaman Tayyar, BPharm \\ Griffith University, Gold Coast Campus, Gold Coast, Queensland, Australia
}

Corresponding Author: Dalia Al-Karawi, Al-Kadhimiya Teaching Hospital, Kadhimiya, Baghdad, Iraq 10006. Phone: +9647901509690. Email: Dalialkarawi@gmail.com

Keywords: curcumin, major depressive disorders

Word count: 4562, number of tables: 2, number of figures: 2 . 


\begin{abstract}
Background: Major depression is a common, recurrent and chronic disease which negatively affects the quality of life and increases the risk of mortality. Several studies have demonstrated that curcumin, the yellow-pigmented substance of the turmeric, possesses antidepressant properties. The aim of this review is to meta-analytically assess the antidepressant effect of curcumin in patients with major depressive disorders.
\end{abstract}

Methods: We extensively searched the literature until August 2015. The random-effect model was used to calculate the pooled standardized difference of means (SMD). Subgroup analyses were also performed to examine the effect of different study characteristics on the overall model.

Results: Six clinical trials met the inclusion criteria. Overall, curcumin administration showed a significantly higher reduction in depression symptoms $(\mathrm{SMD}=-0.34,95 \% \mathrm{CI}=-0.56,-0.13, \mathrm{p}=$ 0.002). Subgroup analyses showed that curcumin had the highest effect when given to middleaged patients $(\mathrm{SMD}=-0.36,95 \% \mathrm{CI}=-0.59,-0.13, \mathrm{p}=0.002)$, for longer duration of administration $(\mathrm{SMD}=-0.40,95 \% \mathrm{CI}=-0.64,-0.16, \mathrm{p}=0.001)$, and at higher doses $(\mathrm{SMD}=-$ $0.36,95 \% \mathrm{CI}=-0.59,-0.13, \mathrm{p}=0.002)$. The administration of new formulation of curcumin (BCM-95) had non-significantly higher effect on depression as compared to the conventional curcumin-piperine formula.

Conclusions: We conclude that there is supporting evidence that curcumin administration reduces depressive symptoms in patients with major depression. 


\section{Introduction}

Major depressive disorders (MDD) are common and disabling conditions which negatively affect the quality of life and increase the risk of mortality (Sivertsen et al. 2015). It is estimated that depression affects almost $16 \%$ of the population on a lifetime basis (Kessler et al. 2005), with a recurrence rate of at least 45\% among these patients (Kruijshaar et al. 2005).

Therefore, depression can perhaps be defined as a profoundly-recurrent chronic condition, with the recurrent nature of the disorder being the main burden for its treatment (Judd 1997).

According to the recommended guidelines, depression is usually treated in episodic fashion during the acute phase of the disease (Davidson 2010), which helps to improve the symptoms in the short term only. Long-term treatment or maintenance of treatment for at least 6 months after remission to prevent relapses was recommended by the National Institute for Health and Clinical Excellence. These recommendations are still under debate concerning the optimal duration of maintenance, which has not yet been thoroughly investigated (Kaymaz et al. 2008). From a clinical perspective, non-adherence to antidepressant medications continues to be high for several reasons (Sansone and Sansone 2012). The adverse effects of antidepressant medications were cited as a major cause of poor compliance to treatment and a limiting factor to the long-term maintenance of antidepressants which is necessary to prevent recurrences (van Geffen et al. 2007). It was reported that up to $50 \%$ of patients with MDD discontinued antidepressant treatment due to the side effects alone (van Geffen et al. 2007), which necessitates an exploration of more tolerable treatment options.

Curcumin (diferuloylmethane), a yellowish pigment present as a component of turmeric (Curcuma longa), was discovered a century ago (Aggarwal and Harikumar 2009). It is a natural phenol which is widely used in South Asian countries as a food coloring and additive. Previous 
studies showed that curcumin possesses antioxidant (Ruby et al. 1995, Sandur et al. 2007, Sahebkar et al. 2013, Sahebkar et al. 2015), anti-inflammatory (Jurenka 2009), and antidepressant (Xu et al. 2005, Kulkarni et al. 2008) qualities. Previous epidemiological studies examined the neuro-protective effect of curcumin and demonstrated that its regular consumption is associated with reduced cognitive function diseases such as Alzheimer disease (Chandra et al. 2001), dementia (Vas et al. 2001), and cognitive deficits in elderly (Ng et al. 2006). Previous review suggests that the neuro-protective effect of curcumin is synergistically boosted by the other components of turmeric; demethoxycurcumin and bisdemethoxycurcumin, in patients with Alzheimer disease (Ahmed and Gilani 2014). The same evidence suggested that each component of turmeric acts through multiple pathways such as decreasing inflammatory stress and attenuation of stress-inducing cytokines which slow down the disease process and improve cognitive function (Ahmed and Gilani 2014).

Several clinical trials attempted to examine the antidepressant effect of curcumin administration in patients with depression. However, the results from these human trials were controversial in regard to whether curcumin can reduce depressive symptoms and enhance the antidepressant effect (Andrade 2014). The present meta-analysis assesses whether curcumin administration can alleviate depression and reduce its symptoms. An investigation of its effect can be an important step to improving depression treatment outcomes and guide future research effort to further assess its clinical effect and application in the treatment of major depression. 


\section{Methods}

\section{Literature Search}

The review protocol has been registered at Prospero International Prospective Register of Systematic Reviews (Registration ID = CRD42015025203). The following databases have been systematically searched for relevant studies during the past 30 years: Pubmed; Scopus; Psychinfo; Evidence Based Medicine (EBM) Guidelines; DynaMed; JAMA evidence and the Cochrane Library. A combination of the following key words were employed to locate relevant studies: Curcumin AND depression OR major depressive disorder AND efficacy OR effect. The search was restricted to studies published in English only. In addition, reference lists of the identified papers were also searched for relevant studies. We followed the guidelines provided in the Preferred Reporting Items for Systematic Reviews and Meta-analysis, the PRISMA statement, to search the literature and present the results (Moher et al. 2009). The identified articles were imported into the EndNote reference management software to remove any duplicates. The titles and abstracts were initially screened for relevance. The full text of the relevant articles was retrieved for further reading and assessment.

\section{Inclusion Criteria}

At the initial stage of the search, six criteria were used to filter the search results Criterion A: only human studies were included; Criterion B: it must be quantitative; Criterion C: studies must have intervention and control groups; Criterion D: studies that addressed curcumin as a key independent intervention were included; Criterion E: only studies that addressed major depressive disorders as an outcome were included; and Criterion F: only studies that measured depression utilizing standardized measurement scales were included. Two independent reviewers screened for potentially relevant articles independently, according to the 
previously specified criteria. A summary of the review is presented in the PRISMA flow chart (figure 1).

\section{Data Abstraction and Quality Assessment}

The abstraction of data and subsequent quality assessment were conducted by two reviewers (Dalia A and Doaa A) independently. A pre-piloted data form was used to extract data from the selected studies. Relevant demographic information such as age, gender, body mass index (BMI), the use of antidepressant medication, and antidepressant class were extracted. Information regarding study design, settings, location, sample size, diagnostic criteria of depression, duration of intervention, dosage of curcumin, addition of absorption enhancers, the type of measurement scale of depression, and major findings were also extracted. The assessment of the abstracted articles was discussed during a consensus meeting. Moreover, the corresponding authors were contacted to obtain missing data.

The Quality Assessment Tool for Quantitative Studies (by the Effective Public Health Project) was utilized to assess the quality of the abstracted articles (supplementary data) ('Quality Assessment Tool for Quantitative Studies' 2008). This tool provides standardized means to appraise study quality which leads to an overall methodological rating of strong, moderate or weak in eight sections: 1 . Selection bias 2. Study design 3. Confounders 4. Blinding 5. Data collection methods 6. Withdrawals and dropouts 7. Intervention integrity 8 . Analysis appropriate to question. The final global rating classifies studies into either strong (no weak ratings), moderate (with one weak rating), or weak (two or more weak ratings) ('Quality Assessment Tool for Quantitative Studies' 2008). Discrepancies in quality assessment were resolved by discussion, reference to Cochrane guidelines or inviting an expert opinion. 


\section{Quantification of depression outcome}

In order to ascertain the assumption that differences in standard deviations among studies do not reflect the differences in depression measurement scales, all studies with inconsistent scales were converted into Hamilton Depression Rating Scale, the 17-item version (HAM-D 17$)$. To convert total scores from the Inventory of Depressive Symptomatology self-rated version (IDS-SR 30 ) scale to equivalent HAM-D ${ }_{17}$ scores, the Ruth et al (2003) method, which is based on Item Response Theory (IRT) analysis, was utilized (Rush et al. 2003). Similarly, to convert depression total scores from the Beck Depression Inventory II (BDI) scale to equivalent HAM$\mathrm{D}_{17}$ scores, the factor-analytic method was used (Vittengl et al. 2005). Because this meta-analysis included some studies with small sample size, Hedge's adjusted $g$ formulation of standardized difference in means was implemented to adjust for small sample bias (Higgins and Green 2011).

\section{Statistical Analysis}

Because the included studies are different in their characteristics, the Random-Effects model and generic inverse variance method were used to combine the results. This model assumes that the inter-study variations are due to both random variation and differences in individual studies as well (DerSimonian and Laird 1986). The individual and combined standardized mean difference (SMD) and the corresponding 95\% confidence interval (CI) were calculated. The standard deviation (SD) of the SMD was calculated according to this formula: $\mathrm{SD}=$ square root $\left[\left(\mathrm{SD}_{\text {pre-treatment }}\right)^{2}+\left(\mathrm{SD}_{\text {post-treatment }}\right)^{2}-\left(2 \mathrm{R} \times \mathrm{SD}_{\text {pre-treatment }} \times \mathrm{SD}_{\text {post-treatment }}\right)\right]$. Because the correlation coefficient $(\mathrm{R})$ value was not reported by the included trials, we assumed that $\mathrm{R}$ value is equal to 0.5 . In order to ascertain that the assumption of $\mathrm{R}$ value did not confound the results of this meta-analysis, a sensitivity analysis was further conducted by repeating the analysis with different $\mathrm{R}$ values ranging from 0.1 to 0.9 . Standard error (SE) was converted to 
SD by the following formula: $\mathrm{SD}=$ S.E. $\times$ square root (number of subjects). In addition, the individual influence of each study was estimated by conducting sensitivity analysis using the leave-one-out method to ascertain the robustness of the results (Higgins 2008), by excluding one study each time and re-examining the changes in the effect size.

Subgroup analyses were also performed subdividing studies according to age group (middle versus old age groups), duration of intervention (6 weeks or more versus less than 6 weeks), dosage of curcumin (1 gram/day versus less than 1 gram per day), addition of absorption enhancers (curcumin plus piperine versus curcumin with no enhancers), presence of other comorbidities (no comorbidities versus comorbidities) and study design/quality of evidence (RCT versus open-label studies), and the effect sizes were recalculated.

Because the number of included studies is small, the heterogeneity between studies was assessed by calculating the $I^{2}$ index that describes the percentage of the variability in effect estimates which is due to inconsistency rather than chance. We assumed that heterogeneity is low, moderate or high when $I^{2}$ is less than $30 \%, 30-50 \%$, or more than $50 \%$, respectively. In addition, publication bias was examined by visual inspection of funnel plot asymmetry. Data were analyzed using the Review Manager software (version 5.3.0) from Cochrane Collaboration.

\section{Results}

Description of the included studies

Of the 1757 studies identified during the initial search, 34 articles were fully retrieved. The full text was assessed according to the previously-stated selection criteria. Of the total, 28 studies were excluded because of either the lack of control or being non-human studies. Six studies met all inclusion criteria. Figure 1 depicts the selection process of the included studies. 
Data were pooled from four RCTs (Bergman et al. 2013, Lopresti et al. 2014, Sanmukhani et al. 2014, Yu et al. 2015), one cross-over (Esmaily et al. 2015) and one open-label study (Panahi et al. 2015). In total, 342 patients were enrolled and completed these studies, with 177 patients in the intervention arm and 165 patients in the control arm. The included studies were published between 2013 and 2015. All these studies enrolled patients diagnosed with major depression who were diagnosed according to standardized tools described earlier. Both intervention and control groups in these studies had antidepressant treatment, while the intervention group also had curcumin and the control group had a placebo. All selected trials quantified major depression as the primary outcome and estimated the effect of intervention utilizing standardized tools. The characteristics of the included trials are summarized in table 1.

Risk of bias assessment

The included studies were appraised according to the Quality Assessment Tool for Quantitative Studies guidelines ('Quality Assessment Tool for Quantitative Studies' 2008), (Supplementary data). The results showed that all included studies had a "strong" global final rating, except Panahi et al (2015) which was classified as having a "moderate" rating (Panahi et al. 2015). The later study did not blind the assessors to which participants where in the intervention or control groups and the patients were aware about the treatment received. Therefore, this study received a "weak" rating in the blinding section, and an overall "moderate" quality of evidence. The difference in effect size between "strong" and "moderate" quality studies was further explored by subgroup analysis, and the effect size was recalculated. 


\section{Clinical effect of curcumin in patients with major depression and subgroup analyses}

Meta-analysis of data from the 6 clinical trials revealed a significant reduction in major depression symptoms following the administration of curcumin $(\mathrm{SMD}=-0.34,95 \% \mathrm{CI}=-0.56$, $0.13, \mathrm{p}=0.002, I^{2}=0 \%$ ) (Figure 2 ). This significant effect size was consistent and not sensitive to any single study involved in this analysis. Subgroup analyses were also performed (Table 2). When the included trials were subgrouped according to the age group of the patients, a significant effect was observed with the middle-age group $(\mathrm{SMD}=-0.36,95 \% \mathrm{CI}=-0.59,-0.13$, $\mathrm{p}=0.002$ ), while curcumin administration had no significant effect among old-age patients $(\mathrm{SMD}=-0.21,95 \% \mathrm{CI}=-0.84,0.42, \mathrm{p}=0.51)$. The pooled data were also stratified according to the duration of intervention. The administration of curcumin for more than six weeks had a profound effect on depressive symptoms, with significant reduction of depression scores $(\mathrm{SMD}=$ $-0.40,95 \% \mathrm{CI}=-0.64,-0.16, \mathrm{p}=0.001)$. On the other hand, shorter period of curcumin administration (less than 6 weeks) resulted in non-significant reduction of depressive symptoms $(\mathrm{SMD}=-0.10,95 \% \mathrm{CI}=-0.58,0.37, \mathrm{p}=0.67)$

All the included trials used the same curcumin dose of $1 \mathrm{~g}$ per day, except the Bergman et al (2013) trial, which administrated $500 \mathrm{mg}$ per day of curcumin (Bergman et al. 2013). Subgroup analysis showed that there was a more significant reduction in depression symptoms when the higher dose of curcumin was administered $(\mathrm{SMD}=-0.36,95 \% \mathrm{CI}=-0.59,-0.13, \mathrm{p}=$ 0.002), while the low dose administration of curcumin yielded non-significant results (SMD = $0.21,95 \% \mathrm{CI}=-0.84,0.42, \mathrm{p}=0.51)$. Further stratification of the pooled data was done according to the addition of the absorption enhancer piperine, the active ingredient in black pepper. Although not significantly different, trials that administrated curcumin with piperine had less effect $(\mathrm{SMD}=-0.33,95 \% \mathrm{CI}=-0.65,-0.01, \mathrm{p}=0.05)$ as compared to the administration of 
curcumin without absorption enhancers $(\mathrm{SMD}=-0.35,95 \% \mathrm{CI}=-0.64,-0.06, \mathrm{p}=0.02)$.

Additionally, the analysis was also stratified according to the presence of other comorbidities in addition to depression. The Esmaily et al (2015) trial only enrolled obese patients (BMI> 30) with an abnormal low density lipoprotein cholesterol level (LDL-C) and risk factors for cardiovascular disease (Esmaily et al. 2015). The results revealed that curcumin administration had more a profound effect on depression among patients with major depression $(\mathrm{SMD}=-0.38$, $95 \% \mathrm{CI}=-0.60,-0.15, \mathrm{p}=0.001)$ in comparison to patients with depression and other comorbidities $(\mathrm{SMD}=0.03,95 \% \mathrm{CI}=-0.68,0.75, \mathrm{p}=0.93)$.

Interestingly, trials with either a "strong" or "moderate" quality rating demonstrated an equally significant effect in reducing symptoms among patients with depression. Data stratification based on the quality of evidence (strong; RCT design versus moderate; open-label design) revealed that clinical trials with a "strong" rating significantly reduced depressive symptoms $(\mathrm{SMD}=-0.28,95 \% \mathrm{CI}=-0.53,-0.04, \mathrm{p}=0.02)$. Similarly, trials with a "moderate" rating had a significant effect in reducing total depression score $(\mathrm{SMD}=-0.53,95 \% \mathrm{CI}=-0.97$, $0.08, \mathrm{p}=0.02)$

Inter-study heterogeneity was assessed utilizing the $I^{2}$ index. The results revealed that the pooled data had minimal heterogeneity which is evident by a non-significant heterogeneity index $\left(I^{2}=0 \%, \mathrm{p}=0.73\right)$. The test for subgroup differences showed that there was a minimal heterogeneity between subgroups, with subgroup difference between middle-age versus old-age groups $\left(I^{2}=6 \%, \mathrm{p}=0.43\right)$; long duration $(\geq 6$ weeks $)$ versus short duration of intervention $(<6$ weeks $)\left(I^{2}=17.7 \%, \mathrm{p}=0.27\right)$; one gram / day versus less than one gram per day $\left(I^{2}=0 \%, \mathrm{p}\right.$ $=0.73)$; presence of other comorbidities versus no associated comorbidities $\left(I^{2}=13.8 \%, \mathrm{p}=0.28\right)$, and "strong" quality rating versus "moderate quality rating of evidence $\left(I^{2}=9 \%, \mathrm{p}=0.53\right)$. 


\section{Adverse events}

However, non-significant adverse effects of curcumin administration were reported among some of the included studies. Lopresti et al (2014) reported one case of digestive complains after administration of curcumin. Similarly, Panahi et al (2015) reported three cases of gastrointestinal complications and two cases of tachycardia and flushing. Gastrointestinal adverse events also seem to be present in the Sanmukhani et al (2014) trial, where gastritis, nausea and giddiness were also reported. Nausea was the only adverse event reported after administration of curcumin in Yu et al (2015) clinical trial, and both Bergman et al (2013) and Esmaily et al (2015) reported no adverse events.

\section{Publication bias}

Visual inspection of the funnel plot (inverse standard error) by effect size (standardized mean difference) showed no evidence of publication bias. In addition, Egger's linear regression did not reveal any statistically significant evidence of publication bias for the assessed outcome (intercept $=0.89$, standard error $=1.97,95 \% \mathrm{CI}=-2.79,3.65, \mathrm{t}=0.52, \mathrm{p}=0.418$ ).

\section{Discussion}

Main findings

We identified 6 clinical trials, with a total of 342 patients diagnosed with major depression, examining the effect of curcumin administration on depressive symptoms. We hypothesized (H1) that the administration of curcumin can enhance the action of antidepressants and alleviate depressive symptoms among patients with MDD. Indeed, the meta-analysis of the included trials demonstrated that the administration of curcumin significantly reduced depressive symptoms $\left(\mathrm{SMD}=-0.34,95 \% \mathrm{CI}=-0.56,-0.13, \mathrm{p}=0.002, I^{2}=0 \%\right)$. Our results were robust and not sensitive to the influence of any single study, as demonstrated by leave-one-out sensitivity 
analysis. Several mechanisms were proposed in an attempt to explain how curcumin may improve the outcome in depression (Tizabi et al. 2014, Kulkarni and Dhir 2010). Hence, the pathophysiology of depression involves over-activation of the inflammatory response which may result in severe detrimental consequences including precipitation of depressive-like behavior (Hayley et al. 2005, Khairova et al. 2009). The well-documented anti-inflammatory properties of curcumin are implicated as a mechanism explaining curcumin's effect in reducing depressive symptoms (Qualls et al. 2014, Aggarwal et al. 2013). Previous meta-analysis suggests that the supplementation with curcumin can reduce circulating C-reactive protein (CRP) — a reliable biomarker of systemic inflammation (Sahebkar 2014). Curcumin is believed to have antiinflammatory effect by suppressing nuclear factor kappa B (NF- $\mathrm{B})$ transcription signaling pathway which is essential for production of pro-inflammatory cytokines (such as interleukin-6 and $1 \beta$ ), which are important for the expression of CRP and other acute phase reactants (Mackiewicz et al. 1991). The anti-inflammatory properties of curcumin was also demonstrated by suppressing systemic inflammatory mediators when given as adjuvant therapy in cancer patients (Panahi et al. 2014).

It is well-documented that major depression is associated with alterations in serotonergic neuronal function in central nervous system which is characterized by reduction in the concentration of active metabolite of serotonin (Owens and Nemeroff 1994). Similarly, dopamine deficiency has also been implicated in the pathophysiology of depression (Kapur and Mann 1992). Previous evidence showed that when curcumin is combined with conventional and newly discovered antidepressants, it enhanced the anti-immobility effect of several antidepressants through enhancing the serotoninergic and dopaminergic systems in animal models (Kulkarni et al. 2008). 
Several other mechanisms were also suggested to explain the antidepressant effect of curcumin (Lopresti et al. 2012). Several reviews confirmed that major depression is associated with decreased total antioxidant status and activation of oxidative and nitrosative pathways (Black et al. 2015, Michel et al. 2012, Palta et al. 2014). The findings from many studies demonstrated that curcumin possesses a potent anti-oxidant quality (Menon and Sudheer 2007, Meng et al. 2013, Du et al. 2012) and it is at least 10 folds more potent as an antioxidant compared to vitamin E (Toda et al. 1985). Therefore, the antioxidant properties of curcumin may also be implicated as an explanation of its antidepressant effect. Other antidepressant modes of action of curcumin were also suggested such as its influence on a range of hormones and neurotransmitters commonly disturbed in depression, its neuroprotective properties and its effect against stress-induced neurotoxicity (Lopresti et al. 2012).

While the evidence remains weak, the subgroup analyses showed that curcumin administration had the highest effect when administrated to middle-aged patients. Late life depression may have different etiology and risk factors in comparison to depression at a younger age (Fiske et al. 2009). The pathological processes of the development of late-onset depression also involve cardiovascular and neurological changes that occur with normal aging, which seem to increase the vulnerability to depression (Fiske et al. 2009). This may explain why the response to curcumin was poor among older patients. These patients may also be more sensitive to the adverse effects of antidepressants (Unützer and Park 2012), which may also implicate nonadherence as a reason for poor response to curcumin administration.

Furthermore, the subgroup analyses revealed that longer duration of curcumin administration (6 weeks or more) and higher dosage (1 gram per day) had the greatest effect at reducing depressive symptoms. Previous evidence suggests that curcumin can up-regulate the 
expression of synapse-associated proteins such as brain-derived neurotrophic factor (BDNF), PSD-95 and Synaptophysin in the Lateral Amygdala in rat model (Zhang et al. 2014). These neurotrophins are essential to protect and maintain the functional integrity of neurons and play a key role in preventing depression (Huang and Reichardt 2001). These neuronal changes induced by curcumin administration may require longer period of time to manifest a significant antidepressant effect. Although dose-response assessment was not undertaken in any of the included trials, previous study demonstrated that curcumin can be given up to 8 grams per day without serious side effects or toxicity (Cheng et al. 2001). Considering the fact that the health benefits of curcumin are restricted by its low solubility, low absorption in the intestine, rapid metabolism and systemic elimination (Wahlstrom and Blennow 1978), the appropriate dose of curcumin to achieve the highest benefits should be assessed and adjusted.

Three trials in this meta-analysis added piperine to enhance the intestinal absorption of curcumin (Bergman et al. 2013, Esmaily et al. 2015, Panahi et al. 2015). Intriguingly, the subgroup analysis revealed that there is no statistically-significant difference in curcumin's effect on depression with or without the addition of piperine. In contrast, those trials that did not administer piperine had a non-significantly higher effect on depression at the same curcumin dosage. It is noteworthy that a patented formulation of curcumin (BCM-95) was administered instead of the conventional curcumin plus piperine in two trials (Lopresti et al. 2014, Sanmukhani et al. 2014). With this formulation, the relative bioavailability of curcumin was assumed to be superior as compared to curcumin-piperine formula (Antony et al. 2008).

Moreover, two trials used a low dosage of piperine (10 mg per day) which may not be enough to enhance the bioavailability of curcumin (Panahi et al. 2015, Esmaily et al. 2015). Only one study used a high dose of piperine (50 mg per day), but it also administered a low dose of curcumin 
(500 mg per day) which may explain why it had no significant effect on depression (Bergman et al. 2013).

Stratification of data based on the presence of other comorbidities showed that curcumin administration had the highest effect when given to depressed patients with no other comorbidities. The results were not significant when curcumin was administrated to obese patients with risk factors of cardiovascular disease and abnormal LDL-C level (Esmaily et al. 2015). It is well-documented that obesity and abnormal lipid profile are associated with overactivation of the inflammatory response and oxidative stress (Monteiro and Azevedo 2010). These stress reactions may influence body response to curcumin and reduce its efficacy.

Curcumin administration was associated with few gastrointestinal adverse events such as nausea, maldigestion and giddiness. This is consistent with previous studies that showed curcumin is generally well-tolerable with no significant side effects, even at higher doses and longer duration (Vadhan-Raj S 2007). This is essentially important, considering the fact that the side effects of antidepressants were cited as a major contributing factor for medication nonadherence among depressed patients (Sansone and Sansone 2012).

\section{Strengths, limitations and implications}

This is the first meta-analysis that has reported on the effect of curcumin in patients with major depressive disorders. The quality of the evidence is high; all the included trials described the placebo-controlled design, selection process, randomization, patient's allocation, blinding, and drop-outs with reasons, except Panahi et al (2015), which was rated as "moderate" due to non-blinding. Moreover, the overall and subgroup heterogeneity was very low. However, there are some noteworthy limitations that should be considered when examining the results of our 
study. First, the number of studies included is small due to limited data, especially for subgroup analyses. Owing to the scarcity of data, the results should be interpreted with caution. Further studies on the effect of curcumin administration in patients with major depression are needed. Second, the dosage of curcumin was limited to 500-1000 mg/ day, which may not be the most optimal to show the actual effect of curcumin on depression. Future studies addressing the doseresponse assessment of curcumin's effect on depression are needed. This is also true regarding the dosage of piperine, and which dose is optimal to enhance curcumin's absorption and bioavailability. Third, the duration of intervention seemed short for some included studies. Because depression is a chronic disease, we will also be interested to observe the long-term effect of curcumin, and whether the observed positive outcome of curcumin administration is sustained. In addition, different measurement scales of depression were used in the included trials and were converted to corresponding HAD- $\mathrm{D}_{17}$ scores utilizing published methods. It is acknowledged that these methods were criticized regarding scale translation at the idiographic level (Hawley et al. 2013). Another limitation is acknowledged regarding the language restriction of the search. Studies published in languages other than English were not included, so it is unknown whether the results from these studies would have modified the reported findings. 


\section{Conclusions}

The findings of this study suggest that curcumin administration is effective in reducing depressive symptoms among patients with MDD. Curcumin is more effective when administrated to middle-aged patients, at higher doses and for longer period of time. The administration of a new formulation of curcumin (BCM-95) had a better effect on depression as compared to the conventional curcumin plus low doses of piperine. In addition, curcumin is well tolerable, with few adverse events reported. Given its high safety and tolerability profile, together with its demonstrated effect, the role of curcumin administration as a new avenue in the treatment of major depression is worth exploring.

\section{Role of funding source}

This study did not receive any grant from any funding agency, commercial or non-for-profit sectors.

\section{Conflict of interest}

The authors declare no conflict of interest.

\section{Acknowledgement}

The authors would like to acknowledge Dr. Luqman Jubair for assisting in contacting the authors to request missing data. 


\section{References}

Aggarwal, B. B., Gupta, S. C. and Sung, B. (2013) 'Curcumin: an orally bioavailable blocker of TNF and other pro-inflammatory biomarkers', Br J Pharmacol, 169(8), 1672-92.

Aggarwal, B. B. and Harikumar, K. B. (2009) 'Potential Therapeutic Effects of Curcumin, the Antiinflammatory Agent, Against Neurodegenerative, Cardiovascular, Pulmonary, Metabolic, Autoimmune and Neoplastic Diseases', The international journal of biochemistry \& cell biology, 41(1), 40-59.

Ahmed, T. and Gilani, A. H. (2014) 'Therapeutic potential of turmeric in Alzheimer's disease: curcumin or curcuminoids?', Phytother Res, 28(4), 517-25.

Andrade, C. (2014) 'A critical examination of studies on curcumin for depression', J Clin Psychiatry, 75(10), e1110-2.

Antony, B., Merina, B., Iyer, V. S., Judy, N., Lennertz, K. and Joyal, S. (2008) 'A Pilot Cross-Over Study to Evaluate Human Oral Bioavailability of BCM-95( $\left.{ }^{\circledR}\right)$ CG (Biocurcumax $\left.{ }^{\mathrm{TM}}\right)$, A Novel Bioenhanced Preparation of Curcumin', Indian Journal of Pharmaceutical Sciences, 70(4), 445-449.

Bergman, J., Miodownik, C., Bersudsky, Y., Sokolik, S., Lerner, P. P., Kreinin, A., Polakiewicz, J. and Lerner, V. (2013) 'Curcumin as an add-on to antidepressive treatment: a randomized, double-blind, placebo-controlled, pilot clinical study', Clin Neuropharmacol, 36(3), 73-7.

Black, C. N., Bot, M., Scheffer, P. G., Cuijpers, P. and Penninx, B. W. (2015) 'Is depression associated with increased oxidative stress? A systematic review and meta-analysis', Psychoneuroendocrinology, 51, 164-75.

Chandra, V., Pandav, R., Dodge, H. H., Johnston, J. M., Belle, S. H., DeKosky, S. T. and Ganguli, M. (2001) 'Incidence of Alzheimer's disease in a rural community in India: the Indo-US study', Neurology, 57(6), 985-9.

Cheng, A. L., Hsu, C. H., Lin, J. K., Hsu, M. M., Ho, Y. F., Shen, T. S., Ko, J. Y., Lin, J. T., Lin, B. R., MingShiang, W., Yu, H. S., Jee, S. H., Chen, G. S., Chen, T. M., Chen, C. A., Lai, M. K., Pu, Y. S., Pan, M. H., Wang, Y. J., Tsai, C. C. and Hsieh, C. Y. (2001) 'Phase I clinical trial of curcumin, a chemopreventive agent, in patients with high-risk or pre-malignant lesions', Anticancer Res, 21(4b), 2895-900.

Davidson, J. R. (2010) 'Major depressive disorder treatment guidelines in America and Europe', J Clin Psychiatry, 71 Suppl E1, e04. 
DerSimonian, R. and Laird, N. (1986) 'Meta-analysis in clinical trials', Controlled Clinical Trials, 7(3), 177188.

Du, P., Tang, H. Y., Li, X., Lin, H. J., Peng, W. F., Ma, Y., Fan, W. and Wang, X. (2012) 'Anticonvulsive and antioxidant effects of curcumin on pilocarpine-induced seizures in rats', Chin Med J (Engl), 125(11), 1975-9.

Esmaily, H., Sahebkar, A., Iranshahi, M., Ganjali, S., Mohammadi, A., Ferns, G. and Ghayour-Mobarhan, M. (2015) 'An investigation of the effects of curcumin on anxiety and depression in obese individuals: A randomized controlled trial', Chin J Integr Med, 21(5), 332-8.

Fiske, A., Wetherell, J. L. and Gatz, M. (2009) 'Depression in Older Adults', Annual review of clinical psychology, 5, 363-389.

Hawley, C. J., Gale, T. M., Smith, P. S., Jain, S., Farag, A., Kondan, R., Avent, C. and Graham, J. (2013) 'Equations for converting scores between depression scales (MADRS, SRS, PHQ-9 and BDI-II): good statistical, but weak idiographic, validity', Hum Psychopharmacol, 28(6), 544-51.

Hayley, S., Poulter, M. O., Merali, Z. and Anisman, H. (2005) 'The pathogenesis of clinical depression: stressor- and cytokine-induced alterations of neuroplasticity', Neuroscience, 135(3), 659-78.

Higgins, J. and Green, S., eds. (2011) Version 5.1.0 ed., The Cochrane Collaboration.

Higgins, J. P. T. (2008) 'Commentary: Heterogeneity in meta-analysis should be expected and appropriately quantified', International Journal of Epidemiology, 37(5), 1158-1160.

Huang, E. J. and Reichardt, L. F. (2001) 'Neurotrophins: roles in neuronal development and function', Annu Rev Neurosci, 24, 677-736.

Judd, L. L. (1997) 'The clinical course of unipolar major depressive disorders', Arch Gen Psychiatry, 54(11), 989-91.

Jurenka, J. S. (2009) 'Anti-inflammatory properties of curcumin, a major constituent of Curcuma longa: a review of preclinical and clinical research', Altern Med Rev, 14(2), 141-53.

Kapur, S. and Mann, J. J. (1992) 'Role of the dopaminergic system in depression', Biol Psychiatry, 32(1), $1-17$.

Kaymaz, N., van Os, J., Loonen, A. J. and Nolen, W. A. (2008) 'Evidence that patients with single versus recurrent depressive episodes are differentially sensitive to treatment discontinuation: a metaanalysis of placebo-controlled randomized trials', J Clin Psychiatry, 69(9), 1423-36. 
Kessler, R. C., Chiu, W. T., Demler, O., Merikangas, K. R. and Walters, E. E. (2005) 'Prevalence, severity, and comorbidity of 12-month DSM-IV disorders in the National Comorbidity Survey Replication', Arch Gen Psychiatry, 62(6), 617-27.

Khairova, R. A., Machado-Vieira, R., Du, J. and Manji, H. K. (2009) 'A potential role for pro-inflammatory cytokines in regulating synaptic plasticity in major depressive disorder', The international journal of neuropsychopharmacology / official scientific journal of the Collegium Internationale Neuropsychopharmacologicum (CINP), 12(4), 561-578.

Kruijshaar, M. E., Barendregt, J., Vos, T., de Graaf, R., Spijker, J. and Andrews, G. (2005) 'Lifetime prevalence estimates of major depression: an indirect estimation method and a quantification of recall bias', Eur J Epidemiol, 20(1), 103-11.

Kulkarni, S. K., Bhutani, M. K. and Bishnoi, M. (2008) 'Antidepressant activity of curcumin: involvement of serotonin and dopamine system', Psychopharmacology (Berl), 201(3), 435-42.

Kulkarni, S. K. and Dhir, A. (2010) 'An Overview of Curcumin in Neurological Disorders', Indian Journal of Pharmaceutical Sciences, 72(2), 149-154.

Lopresti, A. L., Hood, S. D. and Drummond, P. D. (2012) 'Multiple antidepressant potential modes of action of curcumin: a review of its anti-inflammatory, monoaminergic, antioxidant, immunemodulating and neuroprotective effects', J Psychopharmacol, 26(12), 1512-24.

Lopresti, A. L., Maes, M., Maker, G. L., Hood, S. D. and Drummond, P. D. (2014) 'Curcumin for the treatment of major depression: a randomised, double-blind, placebo controlled study', J Affect Disord, 167, 368-75.

Mackiewicz, A., Speroff, T., Ganapathi, M. K. and Kushner, I. (1991) 'Effects of cytokine combinations on acute phase protein production in two human hepatoma cell lines', J Immunol, 146(9), 3032-7.

Meng, B., Li, J. and Cao, H. (2013) 'Antioxidant and antiinflammatory activities of curcumin on diabetes mellitus and its complications', Curr Pharm Des, 19(11), 2101-13.

Menon, V. P. and Sudheer, A. R. (2007) 'Antioxidant and anti-inflammatory properties of curcumin', Adv Exp Med Biol, 595, 105-25.

Michel, T. M., Pulschen, D. and Thome, J. (2012) 'The role of oxidative stress in depressive disorders', Curr Pharm Des, 18(36), 5890-9. 
Moher, D., Liberati, A., Tetzlaff, J. and Altman, D. G. (2009) 'Preferred reporting items for systematic reviews and meta-analyses: the PRISMA statement', Ann Intern Med, 151(4), 264-9, w64.

Monteiro, R. and Azevedo, I. (2010) 'Chronic Inflammation in Obesity and the Metabolic Syndrome', Mediators of Inflammation, 2010, 289645.

Ng, T. P., Chiam, P. C., Lee, T., Chua, H. C., Lim, L. and Kua, E. H. (2006) 'Curry consumption and cognitive function in the elderly', Am J Epidemiol, 164(9), 898-906.

Owens, M. J. and Nemeroff, C. B. (1994) 'Role of serotonin in the pathophysiology of depression: focus on the serotonin transporter', Clin Chem, 40(2), 288-95.

Palta, P., Samuel, L. J., Miller, E. R., 3rd and Szanton, S. L. (2014) 'Depression and oxidative stress: results from a meta-analysis of observational studies', Psychosom Med, 76(1), 12-9.

Panahi, Y., Badeli, R., Karami, G. R. and Sahebkar, A. (2015) 'Investigation of the efficacy of adjunctive therapy with bioavailability-boosted curcuminoids in major depressive disorder', Phytother Res, 29(1), 17-21.

Panahi, Y., Saadat, A., Beiraghdar, F. and Sahebkar, A. (2014) 'Adjuvant Therapy with BioavailabilityBoosted Curcuminoids Suppresses Systemic Inflammation and Improves Quality of Life in Patients with Solid Tumors: A Randomized Double-Blind Placebo-Controlled Trial', Phytotherapy Research, 28(10), 1461-1467.

'Quality Assessment Tool for Quantitative Studies', (2008) [online], available: http://www.nccmt.ca/registry/view/eng/14.html].

Qualls, Z., Brown, D., Ramlochansingh, C., Hurley, L. L. and Tizabi, Y. (2014) 'Protective effects of curcumin against rotenone and salsolinol-induced toxicity: implications for Parkinson's disease', Neurotox Res, 25(1), 81-9.

Ruby, A. J., Kuttan, G., Babu, K. D., Rajasekharan, K. N. and Kuttan, R. (1995) 'Anti-tumour and antioxidant activity of natural curcuminoids', Cancer Lett, 94(1), 79-83.

Rush, A. J., Trivedi, M. H., Ibrahim, H. M., Carmody, T. J., Arnow, B., Klein, D. N., Markowitz, J. C., Ninan, P. T., Kornstein, S., Manber, R., Thase, M. E., Kocsis, J. H. and Keller, M. B. (2003) 'The 16-Item Quick Inventory of Depressive Symptomatology (QIDS), clinician rating (QIDS-C), and self-report (QIDS-SR): a psychometric evaluation in patients with chronic major depression', Biol Psychiatry, 54(5), 573-83. 
Sahebkar, A. (2014) 'Are curcuminoids effective C-reactive protein-lowering agents in clinical practice? Evidence from a meta-analysis', Phytother Res, 28(5), 633-42.

Sahebkar, A., Mohammadi, A., Atabati, A., Rahiman, S., Tavallaie, S., Iranshahi, M., Akhlaghi, S., Ferns, G. A. and Ghayour-Mobarhan, M. (2013) 'Curcuminoids modulate pro-oxidant-antioxidant balance but not the immune response to heat shock protein 27 and oxidized LDL in obese individuals', Phytother Res, 27(12), 1883-8.

Sahebkar, A., Serban, M.-C., Ursoniu, S. and Banach, M. (2015) 'Effect of curcuminoids on oxidative stress: A systematic review and meta-analysis of randomized controlled trials', Journal of Functional Foods.

Sandur, S. K., Ichikawa, H., Pandey, M. K., Kunnumakkara, A. B., Sung, B., Sethi, G. and Aggarwal, B. B. (2007) 'Role of pro-oxidants and antioxidants in the anti-inflammatory and apoptotic effects of curcumin (diferuloylmethane)', Free Radic Biol Med, 43(4), 568-80.

Sanmukhani, J., Satodia, V., Trivedi, J., Patel, T., Tiwari, D., Panchal, B., Goel, A. and Tripathi, C. B. (2014) 'Efficacy and safety of curcumin in major depressive disorder: a randomized controlled trial', Phytother Res, 28(4), 579-85.

Sansone, R. A. and Sansone, L. A. (2012) 'Antidepressant Adherence: Are Patients Taking Their Medications?', Innovations in Clinical Neuroscience, 9(5-6), 41-46.

Sivertsen, H., Bjorklof, G. H., Engedal, K., Selbaek, G. and Helvik, A. S. (2015) 'Depression and Quality of Life in Older Persons: A Review', Dement Geriatr Cogn Disord, 40(5-6), 311-339.

Tizabi, Y., Hurley, L. L., Qualls, Z. and Akinfiresoye, L. (2014) 'Relevance of the anti-inflammatory properties of curcumin in neurodegenerative diseases and depression', Molecules, 19(12), 20864-79.

Toda, S., Miyase, T., Arichi, H., Tanizawa, H. and Takino, Y. (1985) 'Natural antioxidants. III. Antioxidative components isolated from rhizome of Curcuma longa L', Chem Pharm Bull (Tokyo), 33(4), 17258.

Unützer, J. and Park, M. (2012) 'Older Adults with Severe, Treatment-Resistant Depression: "I got my mother back."', JAMA : the journal of the American Medical Association, 308(9), 909-918.

Vadhan-Raj S, W. D., Wang M, Giralt S, Alexanian R, Thomas S, et al. (2007) 'Curcumin downregulates NF-KB and related genes in patients with multiple myeloma: results of a phase $1 / 2$ study', Blood, 110(11), 357a. 
van Geffen, E. C. G., van der Wal, S. W., van Hulten, R., de Groot, M. C. H., Egberts, A. C. G. and Heerdink, E. R. (2007) 'Evaluation of patients' experiences with antidepressants reported by means of a medicine reporting system', European Journal of Clinical Pharmacology, 63(12), 1193-1199.

Vas, C. J., Pinto, C., Panikker, D., Noronha, S., Deshpande, N., Kulkarni, L. and Sachdeva, S. (2001) 'Prevalence of dementia in an urban Indian population', Int Psychogeriatr, 13(4), 439-50.

Vittengl, J. R., Clark, L. A., Kraft, D. and Jarrett, R. B. (2005) 'Multiple measures, methods, and moments: a factor-analytic investigation of change in depressive symptoms during acute-phase cognitive therapy for depression', Psychol Med, 35(5), 693-704.

Wahlstrom, B. and Blennow, G. (1978) 'A study on the fate of curcumin in the rat', Acta Pharmacol Toxicol (Copenh), 43(2), 86-92.

Xu, Y., Ku, B. S., Yao, H. Y., Lin, Y. H., Ma, X., Zhang, Y. H. and Li, X. J. (2005) 'Antidepressant effects of curcumin in the forced swim test and olfactory bulbectomy models of depression in rats', Pharmacol Biochem Behav, 82(1), 200-6.

Yu, J. J., Pei, L. B., Zhang, Y., Wen, Z. Y. and Yang, J. L. (2015) 'Chronic Supplementation of Curcumin Enhances the Efficacy of Antidepressants in Major Depressive Disorder: A Randomized, DoubleBlind, Placebo-Controlled Pilot Study', J Clin Psychopharmacol, 35(4), 406-10.

Zhang, L., Luo, J., Zhang, M., Yao, W., Ma, X. and Yu, S. Y. (2014) 'Effects of curcumin on chronic, unpredictable, mild, stress-induced depressive-like behaviour and structural plasticity in the lateral amygdala of rats', Int J Neuropsychopharmacol, 17(5), 793-806. 
Table 1: The characteristics of the included trials

\begin{tabular}{|c|c|c|c|c|c|c|c|c|c|c|c|}
\hline Studies & 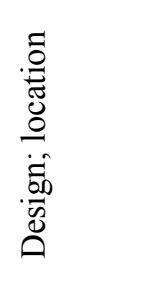 & 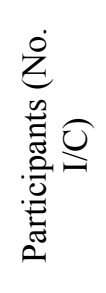 & 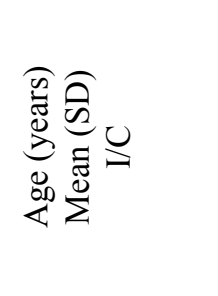 & $\sum_{\substack{x \\
\infty}}^{\substack{\infty \\
\infty}}$ & 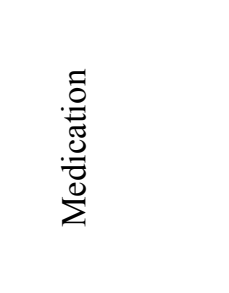 & 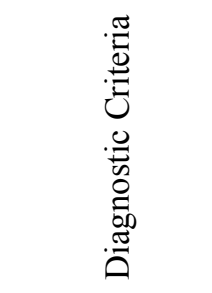 & 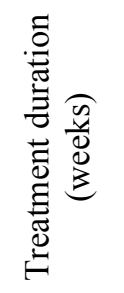 & 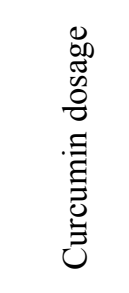 & 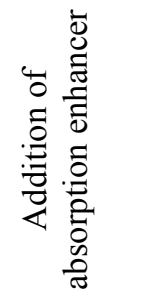 & 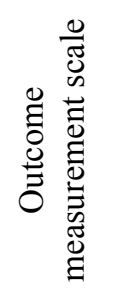 & 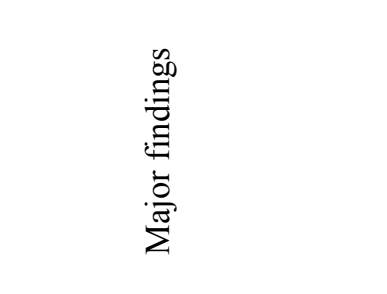 \\
\hline $\begin{array}{l}\text { Bergman et al } \\
2013\end{array}$ & $\begin{array}{l}\mathrm{RCT} \\
\mathrm{DB} ; \\
\text { Israel }\end{array}$ & $20 / 20$ & $\begin{array}{l}65.8(10.7) / \\
61.3(15.2)\end{array}$ & $17 / 23$ & $\begin{array}{l}\text { Escitalopram } \\
\text { or venlafaxine }\end{array}$ & $\begin{array}{l}\text { CGI-S } \geq 4 \\
\text { HAM-D- } 17 \\
>21 \\
\text { MADRS }> \\
22\end{array}$ & 5 & $\begin{array}{l}500 \\
\mathrm{mg} / \text { day }\end{array}$ & $\begin{array}{l}50 \mathrm{mg} \text { of } \\
\text { piperine/ } \\
\text { day }\end{array}$ & $\begin{array}{l}\text { HAM- } \\
\text { D }_{17} \\
\text { MADR } \\
\text { S, CGI- } \\
\text { S }\end{array}$ & $\begin{array}{l}\text { Non-significant reduction, } \\
\text { curcumin group had more } \\
\text { rapid relief of depressive } \\
\text { symptoms }\end{array}$ \\
\hline $\begin{array}{l}\text { Esmaily et al } \\
2015\end{array}$ & $\begin{array}{l}\text { DB } \\
\text { cross- } \\
\text { over; } \\
\text { Iran }\end{array}$ & $\begin{array}{l}\text { Obese } \\
15 / 15\end{array}$ & $\begin{array}{l}38.84(11.12) / \\
37.81(12.31)\end{array}$ & $6 / 24$ & ND & BDI; BAI & $\begin{array}{l}4 ; 2 \\
\text { (wash- } \\
\text { out); } 4\end{array}$ & $1 \mathrm{~g} /$ day & $\begin{array}{l}10 \mathrm{mg} \text { of } \\
\text { piperine/ } \\
\text { day }\end{array}$ & $\begin{array}{l}\text { BDI, } \\
\text { BAI }\end{array}$ & $\begin{array}{l}\text { Non-significant difference } \\
\text { in BDI scores }\end{array}$ \\
\hline $\begin{array}{l}\text { Lopresti et al } \\
2014\end{array}$ & $\begin{array}{l}\text { DB } \\
\text { RCT; } \\
\text { Australia }\end{array}$ & $28 / 28$ & $\begin{array}{l}44.04(11.94) / \\
48.54(11.73)\end{array}$ & $16 / 40$ & Antidepressant & $\begin{array}{l}\text { DSM-IV } \\
\text { IDS-SR }_{30} \\
\geq 14\end{array}$ & 8 & $1 \mathrm{~g} /$ day & $\begin{array}{l}\text { None, } \\
\text { BCM-95 }\end{array}$ & $\begin{array}{l}\text { IDS- } \\
\text { SR }_{30} \\
\text { STAI }\end{array}$ & $\begin{array}{l}\text { Significant reduction of } \\
\text { IDS-SR }_{30} \text { scores for } \\
\text { curcumin group }\end{array}$ \\
\hline Panahi et al 2015 & $\begin{array}{l}\text { Open- } \\
\text { label; } \\
\text { Iran }\end{array}$ & $61 / 50$ & $\begin{array}{l}40.69 \\
(10.04) / \\
40.40(9.56)\end{array}$ & $51 / 60$ & Antidepressant & DSM-IV & 6 & $1 \mathrm{~g} /$ day & $\begin{array}{l}10 \mathrm{mg} \text { of } \\
\text { piperine/ } \\
\text { day }\end{array}$ & $\begin{array}{l}\text { HADS, } \\
\text { BDI }\end{array}$ & $\begin{array}{l}\text { Significant reduction in } \\
\text { both HADS and BDI } \\
\text { scores among curcumin } \\
\text { group }\end{array}$ \\
\hline $\begin{array}{l}\text { Sanmukhani et al } \\
2014\end{array}$ & $\begin{array}{l}\mathrm{SB} \\
\mathrm{RCT} \\
\text { India }\end{array}$ & $20 / 20$ & $\begin{array}{l}40.4(34.1- \\
46.7) / 33.6 \\
(28.9- \\
38.3)^{*}\end{array}$ & $16 / 24$ & Fluoxetine & HAM-D $17>7$ & 6 & $1 \mathrm{~g} /$ day & $\begin{array}{l}\text { None, } \\
\text { BCM-95 }\end{array}$ & $\begin{array}{l}\text { HAM- } \\
\mathrm{D}_{17} \\
\text { CGI-S }\end{array}$ & $\begin{array}{l}\text { Non-significant reduction } \\
\text { in } \text { HAM-D }_{17} \text { scores }\end{array}$ \\
\hline Yu et al 2015 & $\begin{array}{l}\text { DB } \\
\text { RCT; } \\
\text { China }\end{array}$ & $50 / 50$ & $\begin{array}{l}44.14(8.02) / \\
45.22(7.68)\end{array}$ & $100 / 0$ & $\begin{array}{l}\text { Antidepressant } \\
\mathrm{s}\end{array}$ & $\begin{array}{l}\text { HAM-D }_{17} \\
>10 \\
\text { MADRS }>14\end{array}$ & 6 & 1g/day & None & $\begin{array}{l}\text { HAM- } \\
\text { D }_{17} \\
\text { MADR } \\
\text { S }\end{array}$ & $\begin{array}{l}\text { Significant reduction of } \\
\text { depressive symptoms } \\
\text { among curcumin group, } \\
\text { and reduction in } \\
\text { inflammatory cytokines }\end{array}$ \\
\hline
\end{tabular}

*Data are presented as (95\% CI); BAI: Beck Anxiety Inventory; BDI: Beck Depression Inventory II; CGI-S: Clinical Global Impression Severity Scale; DB: Double Blind; DSM-IV: Diagnostic and Statistical Manual of Mental Disorders, $4^{\text {th }}$ edition; HADS: Hospital Anxiety and Depression Scale; HAM-D ${ }_{17}$ : Hamilton Depression Rating Scale, 17-item version; I/C:

Intervention/Control; IDS-SR 30 : Inventory of Depressive Symptomatology self-rated version; MADRS: Montgomery-Asberg 
Depression Rating Scale; ND: Not Determined; RCT: Randomized Controlled Trial; SB: Single Blind; STAI: Spielberger State-Trait Anxiety Inventory

Table 2: Subgroup analysis of the effect of curcumin on depressive symptoms

\begin{tabular}{|c|c|c|c|c|}
\hline Subgroups & No & $I^{2}$ & $\begin{array}{l}\text { Mean difference } \\
\qquad(95 \% \mathrm{CI})\end{array}$ & $\mathrm{P}$ \\
\hline \multicolumn{5}{|l|}{ Age of participants } \\
\hline Middle age & 5 & $0 \%$ & $-0.36[-0.59,-0.13]$ & 0.002 \\
\hline Old age & 1 & $\mathrm{~N} / \mathrm{A}$ & $-0.21[-0.84,0.42]$ & 0.51 \\
\hline \multicolumn{5}{|l|}{ Duration of intervention } \\
\hline Six weeks or more & 4 & $0 \%$ & $-0.40[-0.64,-0.16]$ & 0.001 \\
\hline Less than six weeks & 2 & $12 \%$ & $-0.10[-0.58,0.37]$ & 0.67 \\
\hline \multicolumn{5}{|l|}{ Dosage of curcumin } \\
\hline One gram/day & 5 & $0 \%$ & $-0.36[-0.59,-0.13]$ & 0.002 \\
\hline Less than one gram/ day & 1 & $\mathrm{~N} / \mathrm{A}$ & $-0.21[-0.84,0.42]$ & 0.51 \\
\hline \multicolumn{5}{|l|}{ Addition of absorption enhancers } \\
\hline Curcumin plus piperine & 3 & $6 \%$ & $-0.33[-0.65,-0.01]$ & 0.05 \\
\hline Curcumin without enhancers & 3 & $0 \%$ & $-0.35[-0.64,-0.06]$ & 0.02 \\
\hline \multicolumn{5}{|c|}{$\begin{array}{l}\text { Presence of other comorbidities in } \\
\text { addition to depression }\end{array}$} \\
\hline No Comorbidities & 5 & $4 \%$ & $-0.38[-0.60,-0.15]$ & 0.001 \\
\hline Comorbidity (Obesity) & 1 & N/A & $0.03[-0.68,0.75]$ & 0.93 \\
\hline \multicolumn{5}{|c|}{ Study design and quality of evidence } \\
\hline RCT (strong quality) & 5 & $0 \%$ & $-0.28[-0.53,-0.04]$ & 0.02 \\
\hline Open label (moderate quality) & 1 & $\mathrm{~N} / \mathrm{A}$ & $-0.53[-0.97,-0.08]$ & 0.02 \\
\hline
\end{tabular}

CI: Confidence Interval; N/A: Not Applicable; RCT: Randomized Controlled Trial 

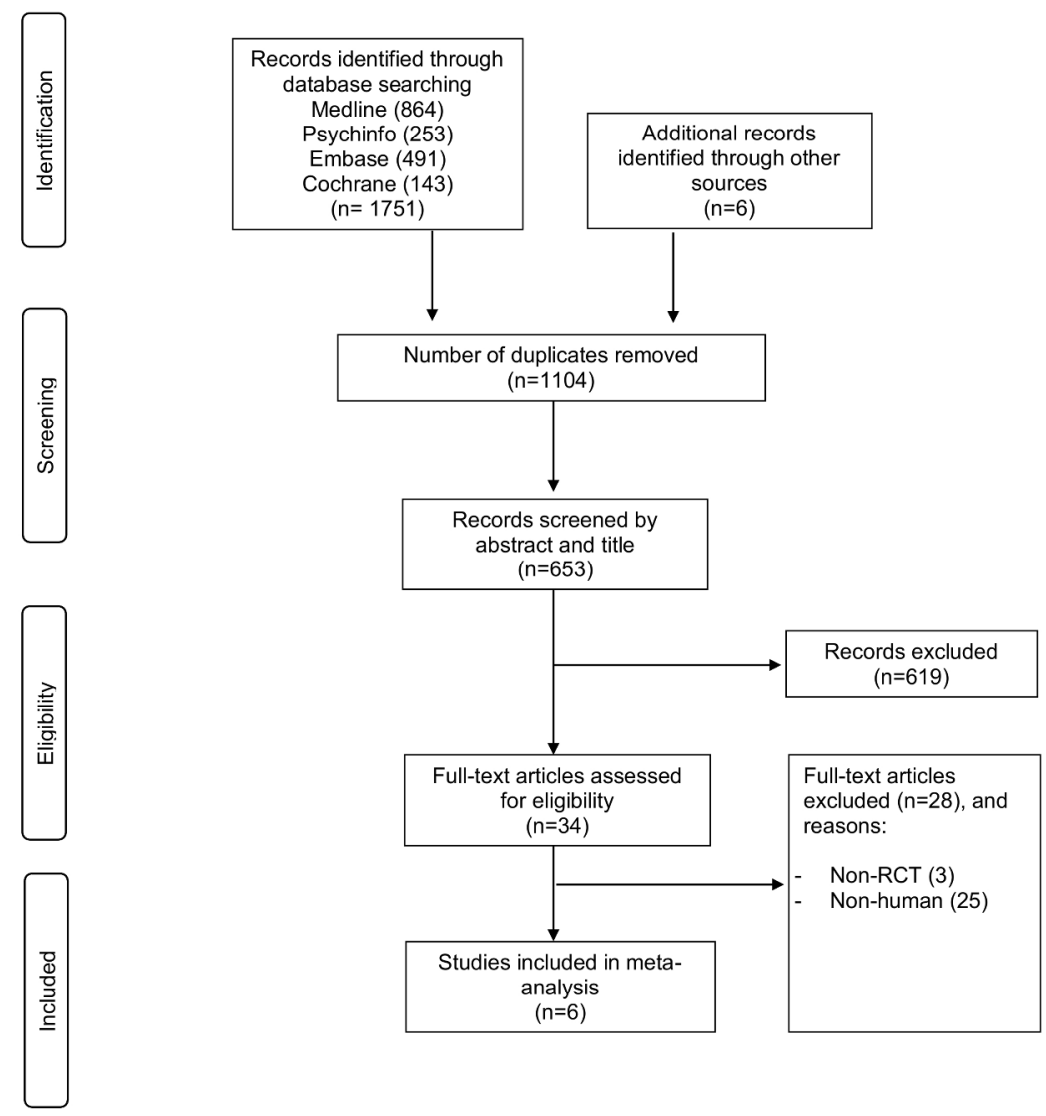

Figure 1. PRISMA flow chart of the literature search

Figure 1: PRISMA flow chart of the literature search $215 \times 279 \mathrm{~mm}(300 \times 300 \mathrm{DPI})$ 
Figure 2: Curcumin effect on depressive symptoms $205 \times 73 \mathrm{~mm}(300 \times 300 \mathrm{DPI})$ 